\title{
PATCH TESTING IN OCCUPATIONAL DERMATOLOGY
}

$\mathrm{D}$ ermatologists use the terms "eczema" and "dermatitis" interchangeably to describe a varied pattern of inflammation which, when acute, is characterised by erythema and vesiculation, and, when chronic, by dryness, lichenification, and fissuring (fig 1). Contact dermatitis is the consequence of a pathological response to one or more external agents that may act either as irritants, where allergic $\mathrm{T}$ cell mechanisms are not involved, or as allergens, where cell mediated hypersensitivity initiates the proceedings. Many studies have shown that it is very difficult to distinguish allergic contact dermatitis from irritant and endogenous forms. ${ }^{1}$

Contact dermatitis is classified into a number of reaction patterns: acute irritant dermatitis is a severe eczematous reaction that results from a single overwhelming exposure, or a few brief exposures to strong irritants or a caustic agent. Chronic (cumulative) irritant dermatitis is characterised by eczematous changes that develop upon repeated exposure to weaker irritants, which are "wet"-for example, water, soaps, detergents, solvents, weak acids or alkalis-or "dry", as in the case of environmental factors like low humidity, heat, air, and dusts. ${ }^{2}$ Many industrial substances are irritants and some are also allergens.

Allergic contact dermatitis is defined as a specific immune phenomenon that is the result of a $\mathrm{T}$ cell mediated immune response to a defined allergen, resulting in eczema or the exacerbation of a pre-existing dermatitis when the patient has been re-challenged with the allergenic material. Common allergens include chromate, rubber chemicals, preservatives, nickel, fragrances, epoxy resins and phenol-formaldehyde resins (box 1). In many cases, several aetiological elements are involved including allergens, irritants, and endogenous factors, especially atopic eczema.

\section{EPIDEMIOLOGY}

Skin disease arising from occupational exposure is common and second only to musculoskeletal disorders as a cause of industrial ill health. Prevalence studies reveal dermatitis (mostly atopic eczema) in about $20 \%$ of the general population at any one time. ${ }^{3}$ Hand dermatitis is present in about $2 \%$ of the people at any one time with a lifetime risk of $20 \%$ in women. ${ }^{4}$ Irritant dermatitis is more common than the allergic type but the latter carries a worse prognosis unless the offending allergen is identified and eliminated.

Accurate estimates of the incidence of occupational skin disease are difficult to find but a recent report from the EPIDERM and OPRA occupational skin disease surveillance project suggests a rate of 13 per 100000 per year ${ }^{5}$ and a prevalence of 15 per 10000 of those ever employed has been quoted. ${ }^{6}$ There may be a perception that industrial skin disease is trivial and does not preclude work but estimates of morbidity argue otherwise. In the USA, $25 \%$ of individuals with occupational skin disease lose a mean of 11 days per year because of their skin problem. ${ }^{7}$

Contact dermatitis makes up about $80 \%$ of all occupational skin disease but other skin problems can result from work exposure. For example, contact urticaria to latex is now seen very commonly, especially but not exclusively in healthcare workers. Infective conditions-for example, herpes simplex in healthcare professions-may go unrecognised as being occupation related, as can skin cancer found, for example, in workers exposed to the sun through prolonged outdoor work or chloracne in chemical workers exposed to noxious substances.

Not surprisingly, different professions have differing risks for occupational skin disease. Those

Correspondence to: Dr David Gawkrodger, Department of Dermatology, Royal Hallamshire Hospital, Sheffield S10 2JF, UK

d.j.gawkrodger@sth.nhs.uk at the highest risk for a contact dermatitis are hairdressers (yearly rate 120/100 000), printers (rate 71/100 000), machine tool operatives (rate 56/100 000), chemical/petroleum plant operatives (rate 45/100 000), assemblers (rate 35/100 000), and machine tool setters (rate 34/ $100000) .^{5}$ 


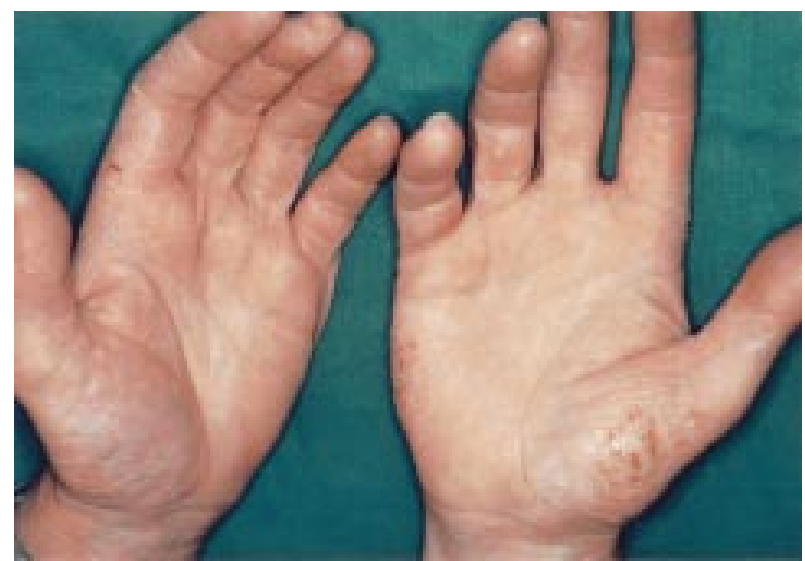

Figure 1 Contact dermatitis of the hands in a dental technician who wore rubber gloves during some of his work. He was found on patch testing to be allergic to the thiuram chemicals, found in rubber as accelerators.

\section{Clinical presentation}

The hands are affected, alone or with other sites, in 80-90\% of occupational cases. The arms can be involved if not covered, and the face and neck are affected if there is exposure to dust or fumes. Cement workers often have lower leg and foot dermatitis in addition to hand changes. Allergy to rubber chemicals can cause dermatitis from rubber gloves or boots. Some workers develop "hardening", an adaptive tolerance to irritants or allergies.

Occupational dermatitis appears at any age but peaks at each end of working life. In bakers and hairdressers, dermatitis appears early. In cement workers, chromate dermatitis requires a few years to develop. Cumulative irritant dermatitis appears after several years' exposure. In the differential diagnosis, contact dermatitis caused by non-occupational exposure and endogenous eczemas need considering. Often occupational dermatitis is multifactorial, with irritants, allergens, endogenous factors, and secondary bacterial infection all causally involved.

\section{Theoretical basis of patch testing}

The patch test was first devised by Jadassohn in 1895 and described in practical detail by Bloch in $1929 .{ }^{\circ}$ The immunological basis of the patch test is the type IV (cell mediated or delayed) hypersensitivity reaction. In this, specifically sensitised $\mathrm{T}$ lymphocytes have secondary contact with the antigen, which is usually in the form of a hapten conjugated with a protein and presented on the surface of an antigen presenting cell (APC). In the skin, the main APCs are the Langerhans' cells and these are mainly located in the epidermis where they form a network. Langerhans' cells are bone marrow derived dendritic cells that are richly endowed with surface receptors including the major histocompatibility class II antigens (for example, HLA-DR) and $\mathrm{T}$ cell receptors that are important for antigen presentation. On encountering an antigen and displaying it on their surface, Langerhans' cells leave the epidermis and migrate to the regional lymph nodes. ${ }^{9}$

On presentation of the antigen by the Langerhans' cell to the mainly CD4+ Th-1 type T lymphocyte, there follows a cascade of release of cytokines that produces $\mathrm{T}$ cell activation and the recruitment of other non-antigen specific $\mathrm{T}$ cells and macrophages to the site, with the result that the reaction and the degree of inflammation is amplified. ${ }^{10}$ Cytokines important for the reaction include interleukin (IL)-1, IL-2, IL-3 and $\gamma$ interferon. Once the reaction gets going most of
Box 1: British Contact Dermatitis Group recommended standard series

Potassium dichromate $0.5 \%$ pet

Neomycin sulfate $20 \%$ pet

Thiuram mix $1 \%$ pet

Paraphenylenediamine 1\% pet

Cobalt chloride $1 \%$ pet

Caine mix IV $10 \%$ pet

Formaldehyde $1 \%$ pet

Rosin $20 \%$ pet

Quinoline mix 6\% pet

Balsam of Peru $25 \%$ pet

Isopropyl PPD $0.1 \%$ pet

Wool alcohols $30 \%$ pet

Mercapto mix 2\% pet

Epoxy resin $1 \%$ pet

Paraben mix $8 \%$ pet

PTBPF resin $1 \%$ pet

Fragrance mix $8 \%$ pet

Quaternium $151 \%$ pet

Nickel sulfate $5 \%$ pet

Methylchloroisothiazolinone + Methylisothiazolinone $0.01 \%$ aq

Mercaptobenzothiazole 2\% pet

Primin $0.01 \%$ pet

Sesquiterpene lactone mix $0.1 \%$ pet

Chlorocresol $1 \%$ pet

Bronopol $0.25 \%$ pet

Cetearyl alcohol $20 \%$ pet

Fucidic acid $2 \%$ pet

Tixocortol pivalate $1 \%$ pet

Budesonide $0.1 \%$ pet

Imidazolidinyl urea $2 \%$ pet

Diazolidinyl urea $2 \%$ pet

Methyldibromoglutaronitrile $0.1 \%$ pet

Ethylenediamine dihydrochloride $1 \%$ pet

PCMX 1\% pet

Carba mix 3\% pet

PTBPF resin, para-tertiary butyl phenol formaldehyde resin; PCMX, 4-chloro 3-xylenol.

the inflammatory cells at the site are not antigen specific, although to initiate the reaction antigen specific cells are essential. The inflammatory reaction reaches its peak at 72 hours and is manifest clinically in the patch test reaction as a localised area of eczema. After 3-4 days, immunological mechanisms downgrade the reaction and it gradually fades away.

In common with most other aspects of medicine, there is evidence that genetically determined factors influence the immune response and hence the ability of an individual to become sensitised and mount an allergic contact dermatitis reaction. Those wishing a detailed discussion of the current immunological theories are referred to $\mathrm{Xu}$ et al. ${ }^{11}$

\section{Comparison with other methods of diagnosis}

An in vitro test for contact allergy, using peripheral blood that contains $\mathrm{T}$ lymphocytes as well as blood monocytes as APCs, has been available for 30 years. The lymphocyte transformation test (LTT) relies on the presence in the peripheral blood of sufficient numbers of circulating Th1 cells specifically sensitised to the allergen in question to be able, when presented with the antigen by a suitable APC, to initiate proliferation of lymphocytes. In the up-to-date models of the LTT, purified fraction of lymphocytes are used and the APCs, usually blood monocytes or Langerhans' cells 


\begin{tabular}{|c|c|c|}
\hline \multicolumn{3}{|c|}{$\begin{array}{l}\text { Box 2: Contact dermatitis hazards in selected } \\
\text { occupations }\end{array}$} \\
\hline Occupation & Irritants & Allergens \\
\hline Bakers & $\begin{array}{l}\text { Flour, detergent, } \\
\text { sugar, enzymes }\end{array}$ & Flavouring, oil, antioxidant \\
\hline Building trade workers & $\begin{array}{l}\text { Cement, glass wool, } \\
\text { acid, preservatives }\end{array}$ & $\begin{array}{l}\text { Cement }(\mathrm{Cr}, \mathrm{Co}) \text {, rubber, } \\
\text { resin, wood }\end{array}$ \\
\hline Caterers, cooks & $\begin{array}{l}\text { Meat, fish, fruit, veg, } \\
\text { detergent }\end{array}$ & $\begin{array}{l}\text { Veg/fruit, cutlery }(\mathrm{Ni}) \text {, } \\
\text { rubber glove, spice }\end{array}$ \\
\hline Cleaners & Detergent, solvent & $\begin{array}{l}\text { Rubber glove, nickel, } \\
\text { fragrance }\end{array}$ \\
\hline Dental personnel & $\begin{array}{l}\text { Detergent, soap, } \\
\text { acrylate, flux }\end{array}$ & $\begin{array}{l}\text { Rubber, acrylate, fragrance, } \\
\text { mercury }\end{array}$ \\
\hline Electronics assemblers & $\begin{array}{l}\text { Solder, solvent, } \\
\text { fibreglass, acid }\end{array}$ & $\begin{array}{l}\mathrm{Cr}, \mathrm{Co}, \mathrm{Ni} \text {, acrylate, epoxy } \\
\text { resin }\end{array}$ \\
\hline Hairdressers & $\begin{array}{l}\text { Shampoo, bleach, } \\
\text { perm lotion, soap }\end{array}$ & $\begin{array}{l}\text { Dye, rubber, fragrance, } \mathrm{Ni} \text {, } \\
\text { thioglycolate }\end{array}$ \\
\hline Metal workers & $\begin{array}{l}\text { Cutting oils, cleanser, } \\
\text { solvent }\end{array}$ & $\begin{array}{l}\text { Preservative, } \mathrm{Ni}, \mathrm{Cr}, \mathrm{Co} \text {, } \\
\text { antioxidant }\end{array}$ \\
\hline Office workers & $\begin{array}{l}\text { Paper, fibreglass, dry } \\
\text { atmosphere }\end{array}$ & $\begin{array}{l}\text { Rubber, Ni, dye, glue, } \\
\text { copying paper }\end{array}$ \\
\hline Textile workers & $\begin{array}{l}\text { Solvent, bleach, fibre, } \\
\text { formaldehyde }\end{array}$ & $\begin{array}{l}\text { Formaldehyde resin, dye, } \\
\mathrm{Ni}\end{array}$ \\
\hline Veterinarians, farmers & $\begin{array}{l}\text { Disinfectant, animal } \\
\text { secretion }\end{array}$ & $\begin{array}{l}\text { Rubber, antibiotics, plants, } \\
\text { preservative }\end{array}$ \\
\hline
\end{tabular}

derived from epidermal suction blisters, are recombined with the $\mathrm{T}$ cells. The proliferation of the lymphocytes is measured using the incorporation of tritiated thymidine to give a stimulation index. ${ }^{12}$

Although the LTT has the attraction of being a blood test and does not require the patient to attend the clinic three or four times, as is needed for patch testing, the LTT is not an easy test for a laboratory to provide; this is because it is labour intensive, needs to be done on a regular basis to provide reliable results, and can only practically be used for one or two antigens, whereas patch testing can be used to assess up to 100 or so allergens. For the moment the LTT remains a research based investigation and the patch test, which uses the patient's biological system, remains the only practical method presently available for assessing cell medicated allergy. The sensitivity and specificity of patch testing is $70-80 \% .^{13}$

\section{Methodology and practical problems}

\section{Taking a history}

It is particularly important to enquire about past and present occupation (that is, possible contact with industrial allergens or irritants), hobbies (for example, contact with plants or animals), cosmetics, and current and previous treatments (potential medicament allergies-for example, to hydrocortisone). All patients are counselled regarding the reason for testing before patches are applied (usually it is to investigate the possibility of an allergic cause or contribution to their dermatitis or eruption).

The possible side effects are explained: irritation on the back from the presence of the patches, the production of an excessive reaction, the worsening of the dermatitis in a number of cases, and the potential that they may rarely be actually sensitised by the process of testing. In view of the latter, it is important that only relevant substances are tested. This will be decided by taking a history. All patients are given written information about what to expect from the procedure and given a contact number to telephone if anything untoward happens.
Series to be tested

This will depend upon the patient's complaint but can be summarised as follows:

Standard series-All patients are patch tested to a standard set of allergens, such as the International, European, North American, or British Contact Dermatitis Group (BCDG) standard series. These include a wide variety of substances found both in the industrial and domestic settings (boxes 2 and 3). ${ }^{14}$ Some patients will also need to be tested to additional preservatives or vehicles-for example, if they use cosmetics or work with coolants. A medicament series is sometimes applied to any patient who has received any form of topical steroid or antibiotic treatment. The standard series will pick up about $80 \%$ of allergens. ${ }^{15}$

Hand dermatitis-Usually the standard series, possibly with additional preservative, vehicle and medicament series, depending on the patient's occupation. The patient should be tested to any additional substances that they bring along, appropriately prepared if necessary.

Hairdressers - Hairdressers with an occupational dermatitis usually have hand involvement. They are tested to the standard, and in addition they receive the hairdressing series. It is not usual to patch test with the hairdressing chemicals which the hairdresser may bring, as they will not be in the appropriate dilutions and most of the chemicals in the appropriate concentrations are already in the hairdressing series.

Plant reactors - Subjects who are suspected of reacting to a plant-for example, housewives, florists, or gardeners-are tested to the plant series in addition to the standard series and possibly other allergens as appropriate.

Metal workers-Metal workers make tools and also undertake lathe work. They are exposed to mineral and coolant oils. They need testing to the standard, preservative, and vehicle series and also to the oil and cooling fluid series together with extra preservatives. They should also be tested to their own coolant oils. These will need to be diluted at $50 \%$ and $10 \%$ (in acetone if the oil is a (non-water soluble) mineral oil, in water if it is a water soluble oil). The preparation of the dilutions should be undertaken by a

\begin{tabular}{|c|c|}
\hline Allergen & Source \\
\hline Acrylates & $\begin{array}{l}\text { Adhesives, sealants, dental work, artificial nails } \\
\text { (beautician), printing }\end{array}$ \\
\hline Chromate & $\begin{array}{l}\text { Cement, tanned leather, primer paint, } \\
\text { anticorrosives, wood preservatives, fire retardants }\end{array}$ \\
\hline Cobalt & Pigment (blue), varnish, paint, ink, metal alloys \\
\hline Colophony & $\begin{array}{l}\text { Glue, plasticiser, adhesive tape, varnish, polish, } \\
\text { paper, insulations, fluxes }\end{array}$ \\
\hline Epoxy resins & $\begin{array}{l}\text { Adhesive, plastics, mouldings, electrical } \\
\text { insulation, surface coating, paints }\end{array}$ \\
\hline Ethylenediamine & $\begin{array}{l}\text { Coolant oils, epoxy-curing agent, electroplating } \\
\text { gel, photographic developing, fungicide }\end{array}$ \\
\hline Formaldehyde & $\begin{array}{l}\text { Preservatives (cutting oils, water-soluble paints), } \\
\text { paper, plastics, clothing }\end{array}$ \\
\hline Fragrance & $\begin{array}{l}\text { Barrier and emollient creams, liquid soaps, } \\
\text { detergents, hair care products, beautician } \\
\text { products }\end{array}$ \\
\hline Nickel & $\begin{array}{l}\text { Electroplating, electronics, garment manufacture } \\
\text { (zips, fasteners), scissors, instruments, protective } \\
\text { clothing, batteries, pigments, catalysts, coins, } \\
\text { jewellery manufacture }\end{array}$ \\
\hline Paraphenylenediamine & Dyes, car tyres, shoes, clothing, colour developer \\
\hline & $\begin{array}{l}\text { Moulds, binders, laminates, surface coatings, } \\
\text { casting sand }\end{array}$ \\
\hline Plants & $\begin{array}{l}\text { Primula obconica, chrysanthemums, garlic, many } \\
\text { cut flowers (for example, Alstroemeria), hardwood } \\
\text { dusts }\end{array}$ \\
\hline $\begin{array}{l}\text { Preservatives (including } \\
\text { biocides) }\end{array}$ & $\begin{array}{l}\text { Coolant oils, barrier and emollient creams, } \\
\text { beautician products }\end{array}$ \\
\hline Rubber chemicals & $\begin{array}{l}\text { Tyres, boots, shoes, belts, gloves, adhesives, } \\
\text { clothing, soluble cutting oils }\end{array}$ \\
\hline
\end{tabular}




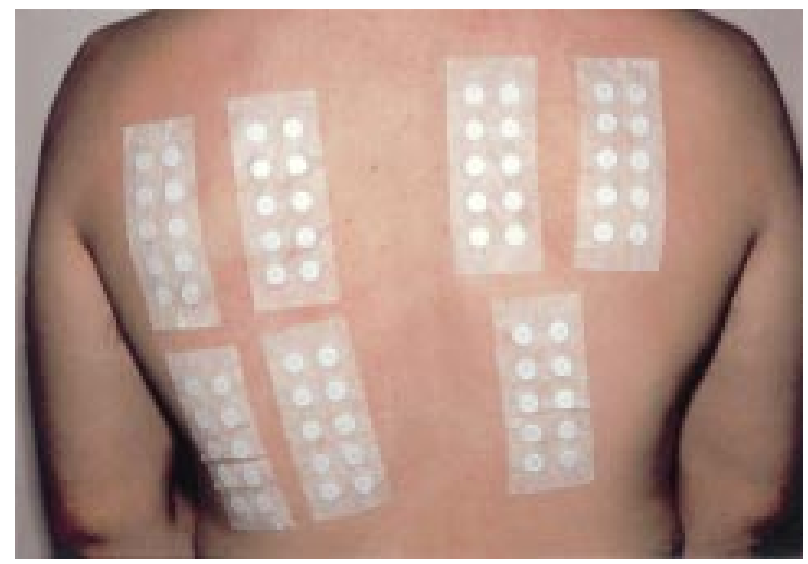

Figure 2 Multiple patch tests are applied to the back during the course of patch testing. The tested materials, purchased in an appropriate concentration (mostly diluted in petrolatum) for testing (or specially prepared for this purpose), are applied to $8 \mathrm{~mm}$ diameter aluminium Finn chambers mounted as a series of 10 chambers on Scanpore tape. These patches are left on for two days, removed and read, and then read again after another two days (that is, four days after first being applied).

pharmacy for mineral oils. The patient will need to provide the data sheets. Data sheets should always be available and looked at whenever any industrial type chemical is applied to a patient.

Bakers and cooks - In addition to the standard series, bakers and cooks are tested to the bakery series and perhaps to additional preservatives and flavourings.

Foot dermatitis-Workers may be allergic to protective footwear. In addition to the standard, patients with foot dermatitis are tested to the shoe series and often to the clothing and dye series as well.

Workers exposed to plastics - In addition to the standard, these patients are tested to plasticiser and glue series, after checking the chemicals to which they are exposed.

Clothing or dye reactions - Some patients may react to protective clothing. The sites of these reactions are usually under the arms, around the waist or in the groin, but they can be anywhere on the parts of the body covered by clothes including the arms and legs. Black or dark blue clothes are the usual culprits. In addition to the usual standard, the clothing and dye series is also applied. If any particular piece of clothing is suspected, then a $2 \mathrm{~cm}$ diameter square of the material should be applied using Scanpore tape to the back.

Rubber glove reactions - Patients who have reacted to rubber gloves need to be tested to the standard series and possibly to preservative, vehicle, and medicament allergens if they have had any form of topical treatment or used hand creams. In addition, they could be tested to the rubber series, although this is often applied at the time of the two day reading when one has had the chance to see if the rubber mixes have come up. These patients should also have had a radioallergosorbernt test (RAST) to latex and may also need prick testing to latex. Also, they can be tested to a piece of glove and lining of glove applied to surface of the skin (in $2 \mathrm{~cm}$ squares on Scanpore).

\section{Testing of patients' own products}

Hand care products, such as emollient creams, can usually be applied "as is". Soaps should not be tested. Industrial chemicals should only be tested if the material has been handed in before patch testing, and the data sheets have been examined by the dermatologist and the materials sent to the pharmacy with the appropriate forms. Cleaning materials and substances of unknown composition are never tested. Potentially irritant or toxic chemicals should not be tested as they can burn a hole in the patient's back. This includes fluxes, caustic chemicals, solvents, acids, and alkalis.

\section{Reading the patch test reactions}

The materials to be patch tested are placed on $8 \mathrm{~mm}$ Finn chambers on Scanpore tape, and then fixed on the upper back (fig 2), taking care to make a note of the location of the tested allergens. The patches are left on for two days. They are then removed, marked, and read with another reading at four days: these are the optimal timings. ${ }^{16}$ The biggest problem in reading patch tests is to differentiate irritant reactions (which have no diagnostic value) from allergic ones (fig 3). Certain substances are known to produce irritant reactions easily - for example, carba mix, fragrance mix, wool alcohols, glutaraldehyde, and benzoyl peroxide. Patients with atopic eczema often produce irritant reactions to nickel sulfate, cobalt chloride, and potassium dichromate. Liquid soaps, even if diluted, can produce irritant changes. There are a variety of types of irritant reactions-some can look identical to allergic reactions. The recognised convention for recording patch test reactions is as follows:

$+/-$ doubtful: faint erythema only

+ weak: erythema, maybe papules

++ strong: vesicles, infiltration

+++ extreme: bullous

IR: irritant

At the time of the four day reading, the results and their relevance, if any, are explained to the patient. Information sheets are given. Occasionally patients may develop a "late" reaction-for example 1-3 weeks after the patches were applied. Gold salts particularly cause this. If the reaction occurs 2-4 weeks after application, this may indicate that sensitisation has occurred. If a late reaction develops, often re-patch test after a suitable period (for example, four weeks) is arranged as it may be difficult to decide exactly which allergen produced the late reaction.

\section{Testing for immediate (type I) hypersensitivity}

Some proteins and chemicals provoke immediate urticaria. The release of mast cell histamine or other mediators may or may not be IgE mediated. Pruritus, erythema, and whealing

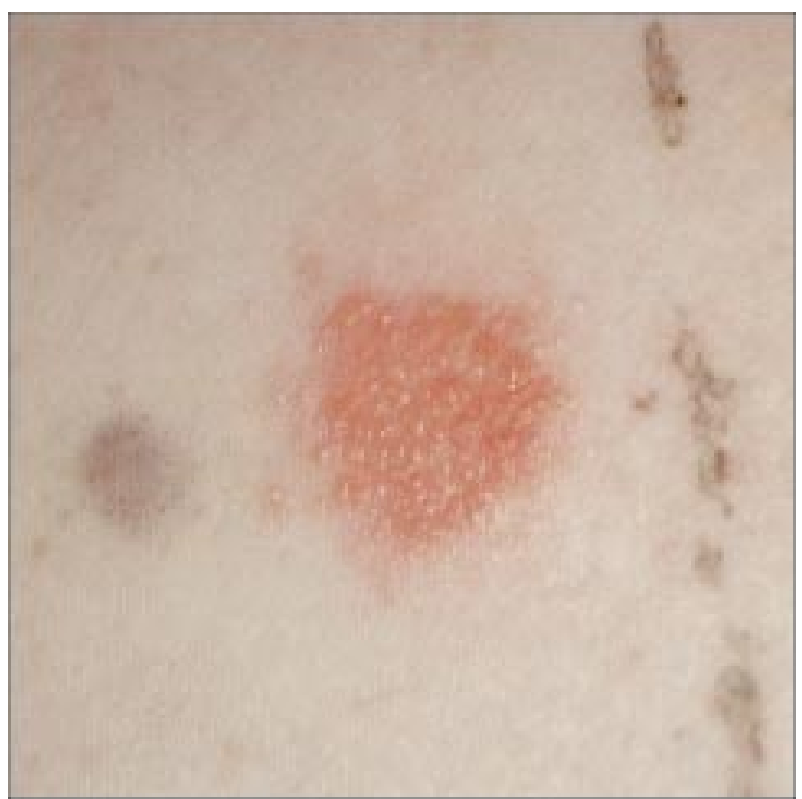

Figure 3 Close up view of an allergic positive reaction, in this case to $5 \%$ nickel sulfate in petrolatum. 
appear within minutes and last a few hours. Occupational contacts include latex in rubber gloves, foods (for example, fish, potato, eggs, flour, spices, meats, and numerous fruits), balsam of Peru (a perfume and flavouring agent), and animal saliva. Contact dermatitis may coexist. Latex contact urticaria is currently a major problem in healthcare workers and in others who wear latex gloves. ${ }^{17} 18$

Prick testing detects immediate (type I) hypersensitivity and is mediated by the antigen triggered $\operatorname{IgE}$ mediated release of vasoactive substances from skin mast cells. Small drops of commercially prepared antigen solutions are placed on marked areas on the forearm and pricked into the skin. The sites are inspected at 15 minutes and a positive result is regarded, by convention, as one showing a wheal of $4 \mathrm{~mm}$ or greater. Patients should have stopped antihistamines 48 hours before the test. Prick tests show some correlation with RAST, which detects allergen specific IgE, but neither test is completely reliable. The risk of anaphylaxis is very small, but resuscitation facilities, including adrenaline (epinephrine) for intramuscular injection and oxygen, are mandatory.

\section{Patch testing and the management of occupational dermatitis}

The management of contact dermatitis is often difficult because of the many and often overlapping factors that can be involved in any one case. It is essential for the physician to understand what the worker actually does in his or her job and a workplace visit may be helpful. The identification of any offending allergen or irritant is a major objective. Patch testing helps identify the allergens involved, if any, and is particularly useful in dermatitis of the hands, face, and feet. The exclusion of an offending allergen from the environment is desirable, and if this can be achieved, the dermatitis may clear. However, most cases of occupational contact dermatitis are of mixed aetiology, and elimination of an allergen may not produce full resolution because there are often irritant and/or endogenous factors at play as well.

It can be difficult to eliminate fully all contact with ubiquitous allergens such as nickel or colophony. Similarly, irritants can be impossible to exclude fully. Some contact with irritants may be inevitable because of the nature of certain jobs, but industrial hygiene often can be improved. Unnecessary contact with irritants should be limited, protective clothing worn (notably polyvinyl chloride (PVC) gloves), and adequate washing and drying facilities provided. Barrier creams are seldom the answer, although they do encourage personal skin care. ${ }^{19}$ Topical steroids (moderately potent or potent) help to suppress contact dermatitis but are secondary to avoidance measures.

\section{Prevention and prognosis}

Reducing the contact time between the skin and noxious substances is the aim. It is achieved by improved work practices (for example, increased automation), substituting an alternative (for example, PVC instead of rubber), the provision of protective clothing, and by the worker taking better care of the skin. Recognising an occupational disease may highlight faulty work practices that can be corrected. Compensation may be due. With regard to prognosis of individuals with occupational dermatitis, it is often not good. A Swedish study showed that only $25 \%$ of 555 individuals with occupational dermatitis healed completely over a 10 year period, and the prognosis was no better in the $40 \%$ who changed job. ${ }^{20}$

\section{Box 4: Key points}

- Occupational skin disease is common and second only to musculoskeletal disorders as a cause of industrial ill health

- The incidence of occupational skin disease in the UK is estimated as 13 per 100000 per year with a prevalence of 15 per 10000 . High risk occupations include hairdressers, printers, machine tool operatives, chemical/petroleum plant operatives, and assemblers

- Contact dermatitis makes up $80 \%$ of all occupational skin disease: it is often multifactorial, with irritant factors often prominent but with endogenous and allergic mechanisms also involved

- Dermatitis of the hand is found in $80-90 \%$ of cases of occupational contact dermatitis

- Occupational dermatitis peaks at the extremes of working life, being early for hairdressers and late in cases of cumulative irritant dermatitis

- Patch testing is an essential part of the investigation of contact dermatitis. It detects cell mediated (type IV) hypersensitivity and requires the in vivo presentation of the allergen by antigen presenting cells to already sensitised lymphocytes, with the subsequent development of a patch of eczema

- Patch tests are done using commercially available pre-prepared allergens applied to the upper back on small aluminium discs on adhesive tape. The patches are left on for two days, removed, and read, and then read again after another two days. The materials applied depend on the patient's occupation and possible exposure

- The reading and interpretation of patch tests is a skilled procedure that should only be done in specialised clinics. Common problems are distinguishing between allergic and irritant reactions and determining the relevance of a reaction

- Type I (immediate) hypersensitivity (for example, in the contact urticaria reaction to latex) needs to be considered and tested for contemporaneously with patch testing

- Once a contact allergen has been identified and thought to be relevant, steps need to be taken to reduce exposure to the substance (for example, protective clothing or improvement in workplace practices) or to substitute another material

- Precautionary measures to avoid contact of workers with known noxious agents should already have been considered when the occupational physician makes a risk assessment of the industrial process

- The prognosis in patients with occupational dermatitis from whatever cause is often poor even if the individual changes their job to avoid contact with the supposed offending substance

\section{References}

1 Agrup G, Dahlquist I, Fregert S, et al. Value of history and testing in suspected contact dermatitis. Arch Dermatol 1970;101:212-15.

2 English JSC, ed. A colour book of occupational dermatology. London: Manson Publishing, 1998.

- A very useful concise yet comprehensive introductory text for medical and nursing staff wanting to know more about occupational skin disorders.

3 Rea JN, Newhouse ML, Halil T. Skin diseases in Lambeth. A community study of prevalence and use of medical care. Br J Prev Soc Med 1976;30:107-14.

4 Agrup G. Hand eczema and other dermatoses in South Sweden. Acta Derm Venereol (Stockh) 1969;49(suppl):61.

5 Cherry N, Meyer JN, Adisesh A, et al. Surveillance of occupational skin disease: EPIDERM and OPRA. Br J Dermatol 2000;142:1128-34.

- An important paper giving details of the incidence rates for occupational skin disease in the UK as reported by dermatologists and occupational physicians. 
6 Health and Safety Executive. Self-reporting work-related illness in 1995. Norwich: HSE Books, 1998.

7 US Bureau of Labor Statistics. Nonfatal occupational illnesses by category of illness, private industry 1992-5. Washington DC: US Department of Labor, 1997.

8 Bloch B. The role of idiosyncrasy and allergy in dermatology. Arch Dermatol 1929;19:175-97.

9 Kimber I, Dearman RJ, Cumberbatch M, et al. Langerhans cells and chemical allergy. Current Opinion in Immunology 1998:10:614-19

10 Kimber I, Dearman RJ. T lymphocyte subpopulations and immune responses to chemical allergens. In: Kimber I, Selgrade MK, eds. T lymphocyte subpopulations in immunotoxicology. Chichester: Wiley, 1998, 199-232.

$11 \mathrm{Xu} \mathrm{H}$, Bjarnason B, Elmets CA. Sensitization versus elicitation in allergic contact dermatitis: potential differences at cellular and molecular levels. Am J Cont Dermatitis 2000;11:228-34.

- A useful review article giving details of current knowledge of the immunology of the contact dermatitis reaction.

12 Everness KM, Gawkrodger DJ, Botham PA, et al. The discrimination between nickel-sensitive and non-nickel sensitive subjects by an in vitro lymphocyte transformation test. Br J Dermatol 1990;122:293-8.

- One of the few studies to examine in depth the validity and diagnostic abilities of the in vitro lymphocyte transformation test.

13 Nethercott J. Positive predictive accuracy of patch tests. Immunol Allergy Clin N Am 1989;9:549-53.

14 Kanerva L, Elsner P, Wahlberg JE, et al, eds. Handbook of occupational dermatology. Berlin: Springer-Verlag, 2000.

- An outstanding large and comprehensive, up-to-date reference textbook giving every detail of all manner of occupationally related cutaneous disorder.

15 Sheretz EF, Swartz SM. Is the screening patch test tray still worth using? J Am Acad Dermatol 1993;36:1057-8.

16 Shehade SA, Beck MH, Hillier VF. Epidemiological survey of standard series patch test results and observations on day 2 and day 4 readings. Contact Dermatitis 1991;24:119-22.

17 Shaffrali FCG, Gawkrodger DJ. Allergic contact dermatitis from natural rubber latex without immediate hypersensitivity. Contact Dermatitis 1999;40:325-6.

- One of the first descriptions of type IV allergic contact dermatitis to natural rubber latex in the absence of type I hypersensitivity.

18 Murphy R, Gawkrodger DJ. Occupational latex contact urticaria in non-healthcare occupations: a report of 3 cases in manual workers. Contact Dermatitis 2000;43:11.

- An important observation of the occurrence of latex contact allergy in manual workers other than those employed in healthcare professions.

19 Goh CL, Gan SL. Efficacies of a barrier cream and an afterwork emollient cream against cutting fluid dermatitis in metal workers: a prospective study. Contact Dermatitis 1994:31:176-80.

20 Fregert S. Occupational dermatitis in a 10-year material. Contact Dermatitis 1975;1:96-107.

- A unique and seminal paper that gave valuable data on the prevalence of occupational dermatitis.

Websites: http://www.gov.sg/mom/wpeaw/ihfile/id.htm and

http://latexallergylinks.tripod.com/
QUESTIONS (See answers on p 785)

(1) Allergic contact dermatitis:

(a) is caused by immediate type hypersensitivity

(b) is due to nickel more commonly in women than in men

(c) is more common in atopics

(d) can be distinguished from an irritant dermatitis

(e) may spread beyond the confines of the allergen's contact

(2) Irritant contact dermatitis:

(a) patch tests may help identify the irritant

(b) is frequent in housewives

(c) may improve with the use of a topical steroid

(d) atopy may be a predisposing factor

(e) relies on immunological recall

(3) Occupational contact dermatitis:

(a) is most common on the face

(b) is more frequently due to irritants than allergens

(c) only occurs when there is a history of endogenous eczema

(d) will occur early in the worker's career if it is going to be a problem

(e) can be diagnosed without patch testing

(4) Patch testing:

(a) if negative, an allergic cause is excluded

(b) irritant reactions help suggest what to avoid

(c) the worker's own materials must always be tested

(d) the individual need not always avoid substances to which they have been shown to be allergic

(e) oral prednisolone can invalidate the test

(5) Latex allergy:

(a) is usually caused by cell mediated immunity

(b) can cause anaphylaxis

(c) in a latex allergic patient, the face may swell if there is contact from a latex glove

(d) is less common in atopics

(e) latex allergic patients complain of food allergies 